\title{
Central Retinal Artery Occlusion Following Cardiac Catheterization
}

\author{
Akio NaKatA, ${ }^{1}$ MD, Yoshiteru SeKiguchi, ${ }^{1}$ MD, Satoshi HiRota, ${ }^{1}$ MD \\ Yoko YAMASHITA, ${ }^{2} \mathrm{MD}$, and Eisuke TAKAZAKURA, ${ }^{1} \mathrm{MD}$
}

\begin{abstract}
SUMMARY
We describe a 66-year-old Japanese man in whom central retinal artery occlusion followed cardiac catheterization. After the procedure, blurred vision was noted in the right eye, and ophthalmological examination revealed an occlusion. Central retinal artery occlusion is a very rare but serious complication of cardiac catheterization. We should anticipate this potential risk to ensure prompt detection and treatment. (Jpn Heart J 2002; 43: 187-192)
\end{abstract}

Key words: Central retinal artery, Occlusion, Cardiac catheterization, Embolism, Complications

Central retinal artery occlusion is a common cause of sudden visual loss. Etiologies of central retinal artery occlusion include atherosclerosis, hypertension, diabetes mellitus, hematologic disease, vascular disease, trauma, inflammation, tumors, and iatrogenic causes. ${ }^{1,2)}$ Well-recognized complications of cardiac catheterization include arrhythmia, myocardial infarction, stroke, allergic reactions, femoral artery pseudoaneurysm, and cardiac perforation. ${ }^{3)}$ We describe a patient with central retinal artery occlusion following cardiac catheterization, a very rare complication of the procedure.

\section{CASE REPORTS}

A 66-year-old Japanese man with a history of hypertension was admitted to hospital in June 2001 because of crushing anterior chest pain at rest. Episodes of chest pain lasting 2 to 3 minutes had begun 8 days prior to admission. Three days prior to admission, he consulted a local physician. Holter electrocardiographic ECG monitoring revealed ST segment elevation coinciding with the chest pain (Figure 1). Physical examination on admission disclosed a blood pressure of 152/

From ${ }^{1}$ Department of Internal Medicine, ${ }^{2}$ Department of Ophthalmology, Kurobe Municipal Hospital, Toyama, Japan.

Address for correspondence: Akio Nakata, MD, Department of Internal Medicine, Kurobe Municipal Hospital, 1108-1 Mikkaichi, Kurobe, Toyama 938-8502, Japan.

Received for publication November 8, 2001.

Revised and accepted November 19, 2001. 
$80 \mathrm{~mm} \mathrm{Hg}$ and a pulse rate of $80 / \mathrm{min}$. Heart and respiratory sounds were normal. No carotid bruits were present.

The 12-lead ECG at the time of admission revealed terminal T-wave inversion in the left precordial leads (Figure 1). A calcium channel blocker (5 mg of amlodipine), a long acting nitrate (40 $\mathrm{mg}$ of isosorbide mononitrate), $81 \mathrm{mg}$ of aspirin, and $200 \mathrm{mg}$ of ticlopidine were administered. Wall motion of the left ventricle was normal according to echocardiography. Neither left ventricular mural thrombus nor calcification of the aortic valve was found.

Cardiac catheterization was performed the next day because of frequent episodes of chest pain. After right heart catheterization with Swan-Ganz catheter insertion via the right femoral vein, a 6Fr sheath was introduced into the right femoral artery. After intravenous administration of 3000 IU of heparin, coronary arteriography was performed using 6Fr Judkins catheters. Coronary arteriography revealed $90 \%$ stenosis of the distal right coronary artery and $75 \%$ stenosis of the proximal left anterior descending artery after the intracoronary administration of $2 \mathrm{mg}$ of isosorbide dinitrate (Figure 2). Because the main etiology of his anginal attack was thought to be vasospasm, we did not perform coronary intervention.

Next, a left ventriculogram obtained using a 6Fr pigtail catheter showed neither a wall motion abnormality nor any left ventricular mural thrombus. The

A

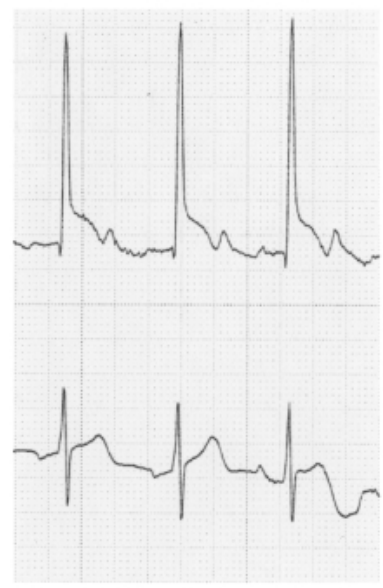

B

I

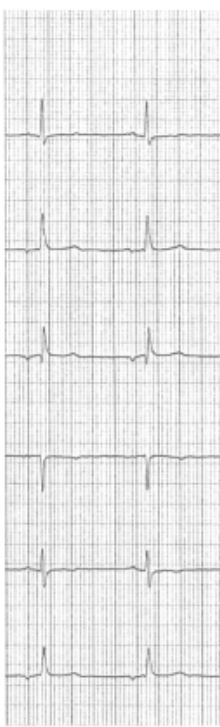

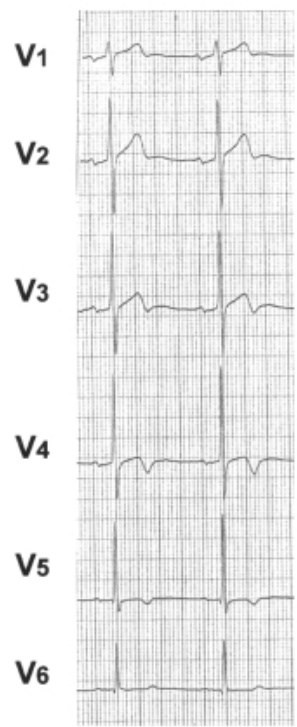

Figure 1. Electrocardiographic (ECG) findings. A Holter ECG recorded prior to admission (A) shows ST-segment elevation. The 12-lead ECG on admission is shown in B. 
patient complained of blurred vision in the right eye during compression of the femoral artery puncture site following catheter withdrawal. The blurring persisted, and the patient was evaluated by the department of ophthalmology the next day. Visual acuity in the right eye was intact only to hand motion. Funduscopic examination revealed occlusion of the right central retinal artery (Figure 3).

A

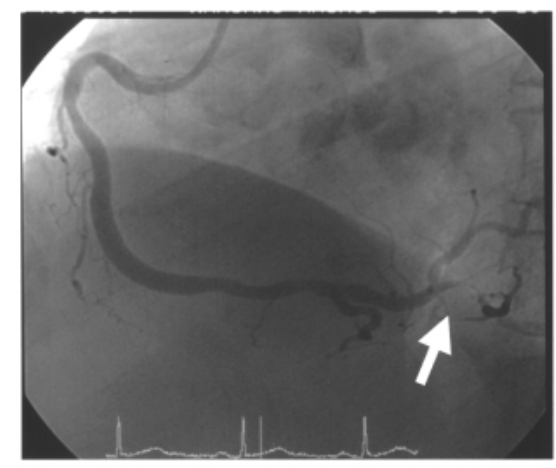

B

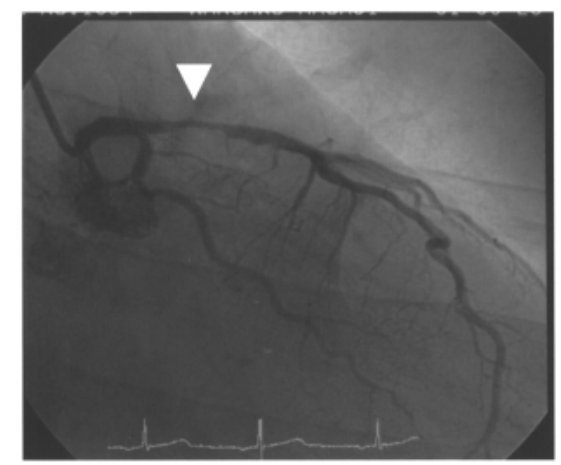

Figure 2. Arteriograms of the right coronary artery in the left anterior oblique projection (A) and the left coronary artery in the right anterior oblique projection (B) show stenosis in the right coronary artery (arrow) and left anterior descending artery (arrowhead).

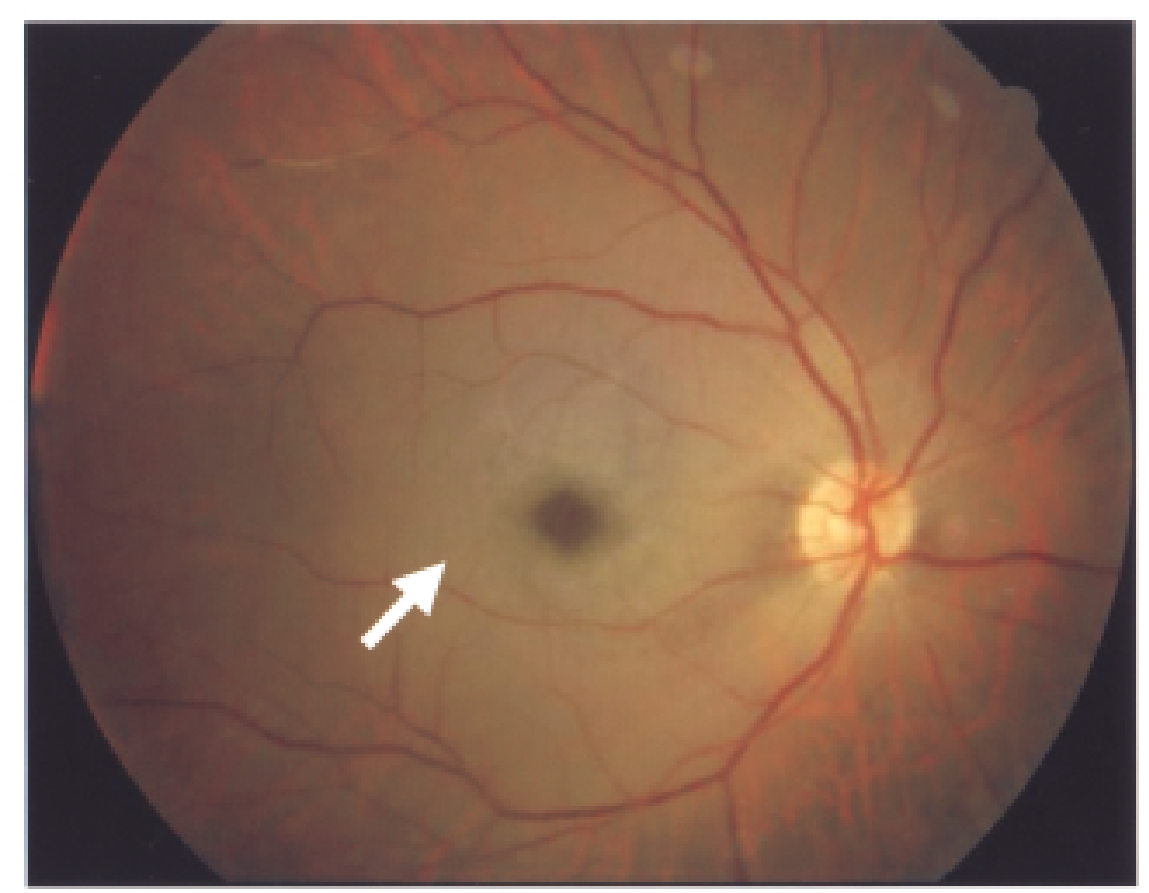

Figure 3. Fundus photograph of the right eye obtained the day after cardiac catheterization. Retinal edema with a cherry red spot (arrow) is noted. 

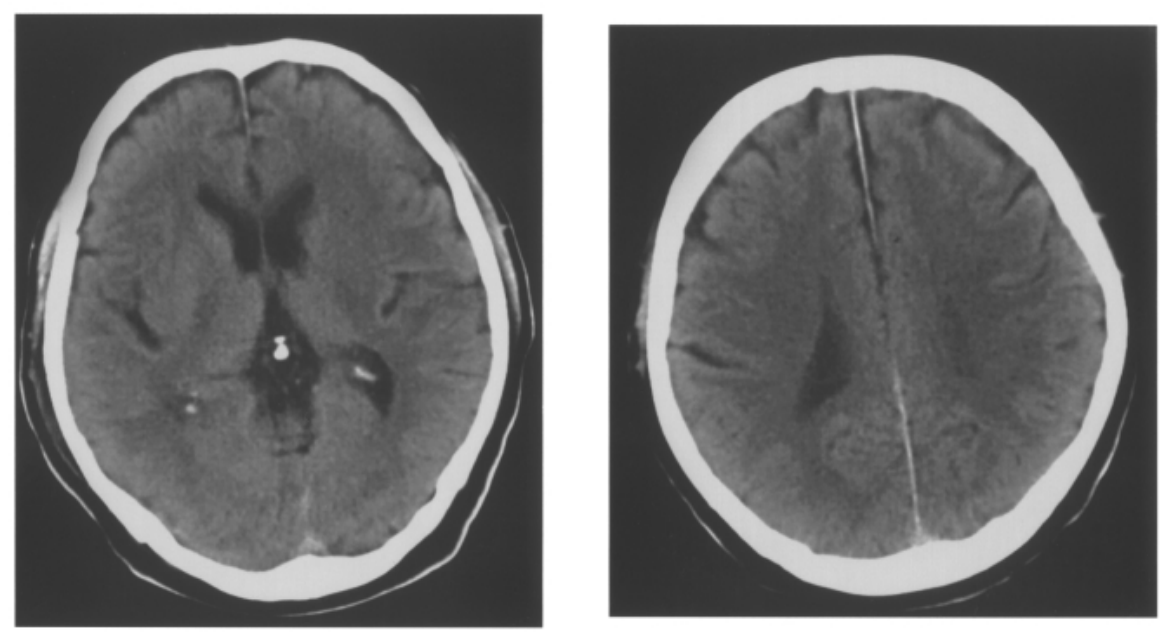

Figure 4. Computed tomography of the brain demonstrates no abnormal findings.

Fluorescein angiography showed that retinal blood flow had been restored by the time of the examination. After diagnosis, urokinase (120,000 IU/day) was administered systemically and hyperbaric oxygen treatments were given without any benefit.

Based on the time course, the patient's right central retinal artery occlusion was considered a complication of cardiac catheterization. Physical examination showed no abnormal neurologic findings, and computed tomography revealed no evidence of cerebral infarction (Figure 4).

\section{DISCUSSION}

To the best of our knowledge, only four cases of central retinal artery occlusion following cardiac catheterization have been reported. ${ }^{4-7)}$ Hallermann, et al reported a case involving central retinal arterial embolization of the fragmented tip of a disposable cardiac catheter that had been reautoclaved and reused. ${ }^{4)}$ Stefansson, et al reported the occurrence of a massive embolus disclosed by direct ophthalmoscopy. ${ }^{5)}$ Kosmorsky, et al described a patient with central retinal infarction associated with multiple cerebral infarctions, and these authors postulated a pathogenesis involving artery-to-artery emboli accompanying catheter manipulations. ${ }^{7)}$ Other investigators did not offer information about how central retinal artery occlusion complicated the cardiac catheterization. In our case, no specific mechanism underlying central retinal artery occlusion was determined. We used new cardiac catheters, and the tip was not broken. 
In general, embolic occlusion is considered the most common cause of retinal infarction. Several investigators have reported central retinal arterial occlusion after carotid angiography. ${ }^{8)}$ Hankey found a high prevalence of atherosclerosis in the cervical portion of the carotids in patients with central retinal artery occlusion, concluding that the major pathogenic event in central retinal artery occlusion was most likely atheroembolism. ${ }^{9)}$ Thus, central retinal artery occlusion following carotid angiography may result from dislodging atheromas within these arteries. Furthermore, atherosclerotic disease of the aortic arch is considered a risk factor for ischemic stroke and a possible source of cerebral emboli. ${ }^{10)}$ Necropsy in patients dying within 6 months following aortography or coronary angiography were reviewed, and revealed evidence of cholesterol embolization. ${ }^{11)}$ In our case, we believe that atheromatous plaque material dislodged from the aortic wall by catheter manipulation embolized to the central retinal artery. The reasons for the lower incidence of central retinal arterial emboli compared to cerebral emboli may be related to differences in blood flow and vessel diameter between the central retinal artery and cerebral artery. A large atheroma was unable to flow to the central retinal artery, whereas a smaller atheroma could not lodge in the central retinal artery.

Central retinal artery occlusion is closely related to cardiovascular disease. ${ }^{12)}$ Patients with central retinal artery occlusion or retinal emboli show an increased mortality rate attributed mainly to cardiac disease and fatal stroke. ${ }^{13)}$ Conversely, patients with cardiovascular diseases are at increased risk for occurrence of central retinal artery occlusion. Cardiac catheterization is an increasingly important tool in the treatment as well as diagnosis of cardiovascular disease. At present, central retinal artery occlusion is not widely recognized as a complication of cardiac catheterization. Although rare, central retinal artery occlusion is a serious complication of cardiac catheterization. The retinal tolerance time has been reported to be 97-98 minutes in an experimental study. ${ }^{14)}$ Digital massage and paracentesis of the anterior chamber are recommended to facilitate recanalization. We can not completely prevent this adverse event, however, awareness of this potential risk and collaboration with ophthalmologists should aid in the prompt diagnosis and treatment of the occlusion.

\section{REFERENCES}

1. Shimizu T, Kiyosawa M, Miura T, Takahashi A, Tamai M. Acute obstruction of the retinal and choroidal circulation as a complication of interventional angiography. Graefes Arch Clin Exp Ophthalmol 1993; 231: 43-7.

2. Castillo B Jr, De Alba F, Thornton J, DeBrun G, Pulido J. Retinal artery occlusion following coil embolization of carotid-ophthalmic aneurysms. Arch Ophthalmol 2000; 118: 851-2.

3. Wyman RM, Safian RD, Portway V, Skillman JJ, McKay RG, Baim DS. Current complications of diagnostic and therapeutic cardiac catheterization. J Am Coll Cardiol 1988; 12: 1400-6. 
4. Hallermann D, Singh G. Iatrogenic central retinal artery embolization: a complication of cardiac catheterization. Ann Ophthalmol 1984; 16: 1025-7.

5. Stefansson E, Coin JT, Lewis WR 3rd, et al. Central retinal artery occlusion during cardiac catheterization. Am J Ophthalmol 1985; 99: 586-9.

6. Sawaguchi S, Abe H, Hasegawa S, Tamura Y. Central retinal artery occlusion developed in a case during coronary angiography. Jpn J Clin Ophthalmol 1995; 49: 1359-61.

7. Kosmorsky G, Hanson MR, Tomsak RL. Neuro-ophthalmologic complications of cardiac catheterization. Neurology 1988; 38: 483-5.

8. Carlson MR, Pilger IS, Rosenbaum AL. Central retinal artery occlusion after carotid angiography. Am J Ophthalmol 1976; 81: 103-4.

9. Hankey GJ, Slattery JM, Warlow CP. Prognosis and prognostic factors of retinal infarction: a prospective cohort study. BMJ 1991; 302: 499-504.

10. Amarenco P, Cohen A, Tzourio C, et al. Atherosclerotic disease of the aortic arch and the risk of ischemic stroke. N Engl J Med 1994; 331: 1474-9.

11. Ramirez G, O'Neill WM Jr, Lambert R, Bloomer HA. Cholesterol embolization: a complication of angiography. Arch Intern Med 1978; 138: 1430-2.

12. Wilson LA, Warlow CP, Russel RW. Cardiovascular disease in patients with retinal arterial occlusion. Lancet 1979; 10: 292-4.

13. Savino PJ, Glaser JS, Cassady J. Retinal stroke; is the patient at risk? Arch Ophthalmol 1977; 95: 1185-9.

14. Hayreh SS, Weingeist TA: Experimental occlusion of the central artery of the retina. Retinal tolerance time to acute ischemia. Br J Opthalmol 1980; 64: 818-25. 